\title{
Isao Takahata : Inspiring Visual Styles of Japanese Film \& Anime Aesthetics
}

\author{
Dahlan Bin Abdul Ghani, Nur Athirah Bt. Ahmad Azizi, Luqman Zulhilmi Bin Abdul 'Alim
}

\begin{abstract}
The Tale of Princess Kaguya is an adaptation from The Tale of the Bamboo Cutter, a classical Japanese folktale, directed by Isao Takahata in Studio Ghibli productions. Isao Takahata is a director who has long been overlook by his longtime colleague and Studio Ghibli co-founder Hayao Miyazaki. The purpose of research about cinematography techniques or style of Isao Takahata animated film in The Tale of Princess Kaguya. The Princess Kaguya animated film is like an old Japanese painting that is similar to traditional sumi-e. The focus of this research will look into several aspects such as impressionistic style and the character design in Princess Kaguya animated film. Impressionistic art is an art style when an artist looks into situation or things with a short glimpse and paint it back using bright and vibrant colors. Most of the pictures are outdoor scenes. The concept character of Princess Kaguya created with amazing work of art using hand-drawn animation to new heights of fluidness.
\end{abstract}

Keywords: cinematography, Princess Kaguya, Studio Ghibli, Isao Takahata, impressionistic style, character design.

\section{INTRODUCTION}

\subsection{History of Studio Ghibli}

Tokuma Shoten is a publisher of Studio Ghibli, who produced "Nausicaa of the Valley of the Wind" in 1985 at the time of making "Laputa in the Sky" as a result of the contentive box office success of "Nausicaa of the Valley of the Wind". It is an animation studio established as the center. Since then, he has produced mainly animated films for theater directed by Hayao Miyazaki and Isao Takahata. By the way "Ghibli" is hot air blowing in the Sahara Desert. During World War II, Italian military reconnaissance aircraft used it as a name, but Miyazaki of airplane enthusiast knew this and it was a studio name.

The principle of Studio Ghible used a feature animation for a theater, not only an original work but a studio that is a very unique worldwide presence in Japan rather than in the animation circle. This is because it is common sense that a theatrical work that cannot obtain a guarantee of box office puts in television, animation series that can earn income continuously, because the risk is too big. In Japan, it is too common that many animation studios build on the theme of television animation, sometimes making theatrical works. And most of the movies for theaters made in Japan, in the

Revised Manuscript Received on September 10, 2019.

Dahlan Bin Abdul Ghani, University Kuala Lumpur, Malaysian Institute of Information Technology, 1016 Jalan Sultan Ismail, 50200 Kuala Lumpur, Malaysia.

(E-mail: dahlan@unikl.edu.my)

Nur Athirah Bt. Ahmad Azizi, University Kuala Lumpur, Malaysian Institute of Information Technology, 1016 Jalan Sultan Ismail, 50200 Kuala Lumpur, Malaysia.

(E-mail: catsatyra94@gmail.com)

Luqman Zulhilmi Bin Abdul 'Alim, Limkokwing University, Inovasi 1-1, Jalan Teknokrat 1/1, 63000, Cyberjaya, Malaysia.

(E-mail: luqmanzulhilmi999@yahoo.com) most cases, they make movies of animated television and has a good reputation. However, the Ghibli was not managed by the present system from the beginning. Takahata and Miyazaki, the men who are now the center of Ghibli together were over 30 years ago in the first place. Toei Animation which the two of which were affiliated was still making only feature animations for theaters. Some of them participated in the production of feature works, but they had to transfer the active stage to the television along with the flow of the times.

However, as they produce such a group of works, they are going to build realistic and high-quality animation that they are aiming for they enter deeply into the psychological description of human beings and express their joy and sadness of life with rich expression power It will reach the conclusion that it will be impossible even with a medium with limited constraints both on budget and on schedule, to realize as it is realized. That was the driving force behind the establishment of Ghibli after the "Nausicaa of the Valley of the Wind". Put all the energy into the work one by one with the budget and schedule, always aiming for content with uncompromising eye-catching eyes. Moreover, they have two directors, Miyazaki and Takahata, and make it with director-centricism. In the twenty years of Ghibli, while maintaining this attitude, the history which has barely accomplished by the superior ability of both directors and the staff's efforts to overcome the difficult task of keeping commercial success and management of the studio compatible It can be said that it is.

To tell the truth, no one thought that the ghibli will continue so far. If one succeeds it will do the following. If it fails it is over. It was because of this way of thinking at first. Therefore, they didn't hire employees to reduce risk; they are collected about 70 staff for each work and took the style of dissolving when completed. The place is a one floor of a lent building of Kichijoji, Tokyo. Actually, this policy was created by Isao Takahata. He produced "Nausicaa of the Valley of the Wind", but the practical ability that showed at that time was also demonstrated greatly at the beginning of Ghibli. And "Laputa Castle in the Sky" was also produced by Isao Takahata Produce · Director Hayao Miyazaki.

"Nausicaa of the Valley of the Wind" was opened to the public in 1984, 91 thousand people; "Castle in the sky Castle Laputa" was mobilized in the Japanese domestic and 775 thousand people in 1986, respectively, and received a high reputation (Ghibli, 2005-2017). 


\subsection{Isao Takahata Background}

Isao Takahata is an animator, film director, screenwriter and producer who gained critical international acclaim for his work as a anime films director. Takahata's recent film is The Tale of the Princess Kaguya. The film was nominated for an Academy Award in the category Best Animated Feature Film at the 87th Academy Awards. According to Hayao Miyazaki, "Music and study are his hobbies".

Isao Takahata was born in the same town with Kon Ichikawa, while Japanese film giant Yasujirō Ozu was raised by his father in Matsusaka. Isao Takahata is an unusual director, especially for an anime director, given that he was never trained as an animator. Takahata's films tend to be focused around mundane everyday experiences, where as his close friend and collaborator, Hayao Miyazaki, tends to make larger scale epics or family fantasy movies. Initially, Kaguya was supposed to be released simultaneously with Miyazaki's film The Wind Rises (2013), but was released several months later due to falling behind schedule (Belton, 2016).

Takahada officially returned to the big screen with The Tale of Princess Kaguya after an absence of 14 years.

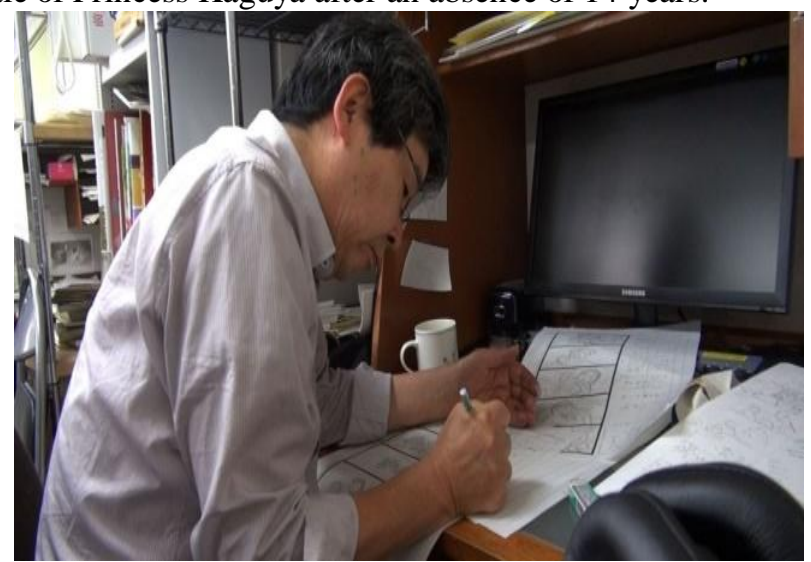

Figure 1.4.1 Isao Takahata doing storyboard The Tale of Princess Kaguya

\subsection{The narrative of Princess Kaguya}

Tells when Sanuki no Miyatsuko, a bamboo cutter, has discovered a mysterious little girl in a bamboo stalk. He and his wife decided to raise her as a princess. Kaguya hime grows rapidly like a bamboo tree and her called name as "Tekenoko" (Little Bamboo) from other village children. Her mother is scared of changes and wants a comfortable life for her adopted daughter, while her father foresee great futures. He saw Kaguya as a part of divine plot and after clothes and gold came out shooting off the bamboo stalks, he made a conclusion that the heavens wanted her to be a proper princess. He thought that was the best way to make his daughter happy instead of asking her what she desires (Friesen, 2014). "Princess Kaguya" storyline is based on a Japanese oldest folklore "The Tale of the Bamboo Cutter".

Isao Takahata change it to a flexible story by defining that Princess Kaguya as a realistic girl. The film consist of various outlandish scenes. The important part of the film is the extraordinary illustrated life and emotions of the heroins. Isao Takahata says, "The animations tend to deprive children of their own imagination by pushing them someone else's fantasy. We have to create another animation which can make them imagine by themselves" (labelleequipe25, 2013). Princess Kaguya's plot is a simple with most viewers will be more immediately understanding by the incredible art style. The story contains both hope and tragic, and also the perfect dialogue adds it up. Joe Hisashi soundtrack is exquisite and the voice overs are massively fascinating. To conclude it, the animated film is a masterpice from every angles, one of the finest releases and arguably the greatest animated movies ever made in Studio Ghibli (Zobras, 2014)

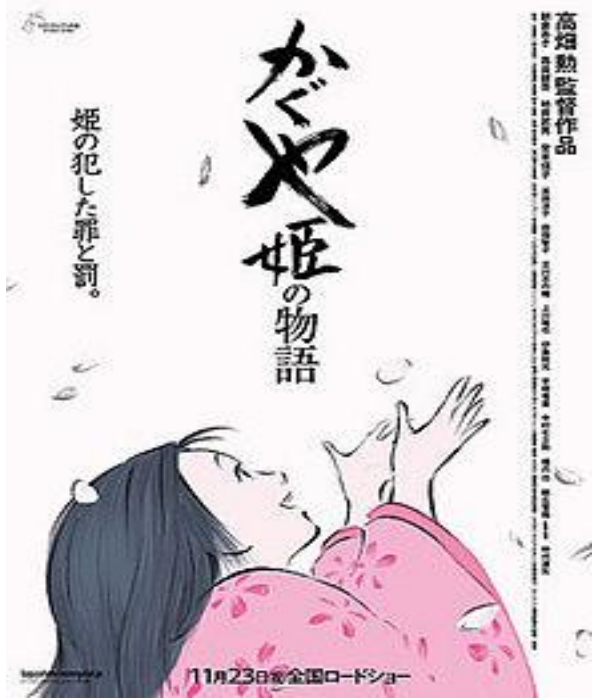

Figure 1.2.1 Japanese theatrical release poster

\subsection{Film production achievements}

This film was adaptation of the 10th-century Japanese folk tale Taketori Monogatari that has previously inspired such cinematic adventures as Kon Ichikawa's live-action film of Princess from the Moon in 1987. The Tale of the Princess Kaguya is a fantasy Japanese animated film in 2013 produced by Studio Ghibli which is directed and co-written by Isao Takahata and is based on a Japanese folktale, The Tale of the Bamboo Cutter. This is Takahata's fifth film for Studio Ghibli and his first since My Neighbors the Yamadas in 1999's. The film was released on November $23^{\text {rd }} 2013$.

The film gained recognition and nominated for the Academy Award at the $87^{\text {th }}$ Academy Awards for Best Animated Feature (Eric, 2015).

\subsection{Art style used in The Tale of Princess Kaguya}

Isao Takahata used a live film technique with different camera angles and shots to create a mood make audiences understand the storyline. Isao Takahata takes the concept character that he created and draws it where we viewers see what a particular character sees from a different angle also a great way to introduce the idea of the subjective shot. The art style used in the animated film is very different from other Studio Ghibli movies. Even though the film looks as though it is entirely hand drawn but it is digitally colored. The 2D animation is complex, yet appears still to be handdrawn.

Variation of the thickness and density of the outlines, with colored areas which not always reach to the outline. Apparently, the figures and backgrounds looks equally the

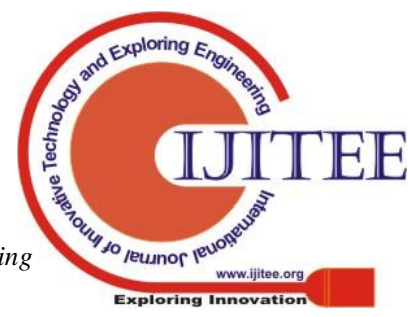


same which in this case is all is colored with pastels. It looks like 'My Neighbors the Yamadas' had been used as the initial sketches which then finished as a result (chuck-526, 2015). The techniques impressionistic style, which is reminiscent of eastern brush paintings, the water color and ink art of ancient Japan. It's an art of charcoal lines and watercolour hues that using brushes strokes upon fibrous paper as the proudly hand-drawn action unfolds, skittish motion drawing our attention to the old-fashioned artistry of key collaborators Osamu Tanabe and Kazuo Oga (Kermode, 2015).

The animation used in The Tale of Princess Kaguya is similar to traditional sumi-e watercolor paintings. Graceful long strokes are used for calmer, relaxed scenes, whereas rushed; jagged lines emphasize frenzied, stressed situations. The tale of princess Kaguya is an artistic masterpiece that successfully ventures into the problematic reality of desire made by Isao Takahata. Isao Takahata has added a lot of development to the magical princess found in the bamboo stalk, creating an intensely moving story in the process. With expressive style helps to show how Kaguya adapts to be whoever the people around her want or expect, especially when she's very young (Anders, Don't Deprive Yourself Of Seeing The Beauty Of Princess Kaguya, 2014).

Throughout this whole research, the objectives for my studies are as following:

1.8.1 To study how the animation technique or style that was used in the animated film of The Tale of Princess Kaguya.

1.8.2 To study how Isao Takahata created the character design based on a folktale into describing Princess Kaguya as a realistic girl in an animated film. Throughout this research, I came out with few problem statements that are related to my topic:

1.9.1 The Animation in Malaysian still lack to produce 2D animated film. with The Malaysian film has a good storyline but the animation itself still lack from many aspects. Film animation Malaysia must improve the better quality or the same level as Japanese animation or the West in terms of the storyline, acting, character development, background, lighting and color.

1.9.2 The techniques use by the Studio Ghibli to produce animated film that will give impact of the development in animation industries? The animation industries in Malaysia must also come out something new that able to create the story in 2D animated film production based on the fairytale Malaysia that can provide moral value such as the Studio Ghibli's films. Examples such as 2D animated film Putih adaptation from fairytale Bawang Putih BawangMerah.

\subsection{Conclusion}

Princess Kaguya's plot is a simple with most viewers will be more immediately understanding by the incredible art style. Isao Takahata has been producing 2D animated film based on the Japanese folktale that can provide moral value. Most of the artwork in the film use hand-drawn, almost like a traditional painting Japanese such as using with a heavy brush strokes. He narrates the story was very interesting that able to touch the audience feeling like animated film Princess Kaguya. The important is the main target audience. Children and adult have a different way of seeing things.
This animated film maybe simply bored and confused for those the younger audiences. For those who love of classic tales and Japanese culture is good to watch and will not regret for this movie.

\section{RELATED WORK}

\subsection{Introduction of Research}

This chapter will review more detail about The Tale of Princess Kaguya style of art that show how Isao Takahata applied into the concept of art and background story Princess Kaguya. This chapter is divided into four subchapters; introduction, impressionistic style and the character design.

\subsection{Impressionistic Style}

In a research article of this subchapter will show some article about impressionistic style. The visual style of Princess Kaguya may appear bland and at times border on unfinished and also simple visual composition. The story and the character become more interesting because the color of the film production that used to makes the audience's emotional that make the response towards the movie. Colors can affect someone moods and feelings. Same to the Takahata's style in this movie, I will review some researches that analyses how Takahata applying the cinematography by he used impressionistic style to moving interplay of brush or pen strokes, charcoal lines and lightly brushed colors to the animated film.

Based on P-J Van Haecke's (2014) article, in The Tale of Princess Kaguya, Takahata with favors an impressionistic style, which is reminiscent of eastern brush paintings, the water color and ink art of ancient Japan. Besides being an impressionistic painting of the Heian aristocratic world, the moving interplay of brush or pen strokes, charcoal lines and lightly brushed colors aims to accentuate the purity and beauty of the nature, the fauna and the flora. But more importantly the animation aims to be a celebration of the purity and beauty of movement as such. The passages where Kaguya-hime runs for example are a feast for the eyes, while these scenes there are many others as well at same time also move the spectator emotionally. The art makes the story, which is not that complex, stronger. The art in itself is emotionally invested through the story. This is one of the reasons why the animation, supported by a sublime soundtrack, has the intrinsic ability to touch people emotionally. In the running scenes, the drawing and animation happens with rougher pen strokes and a more muted color palette, which induce an emotional response in the viewer (Haecke, 2014). 


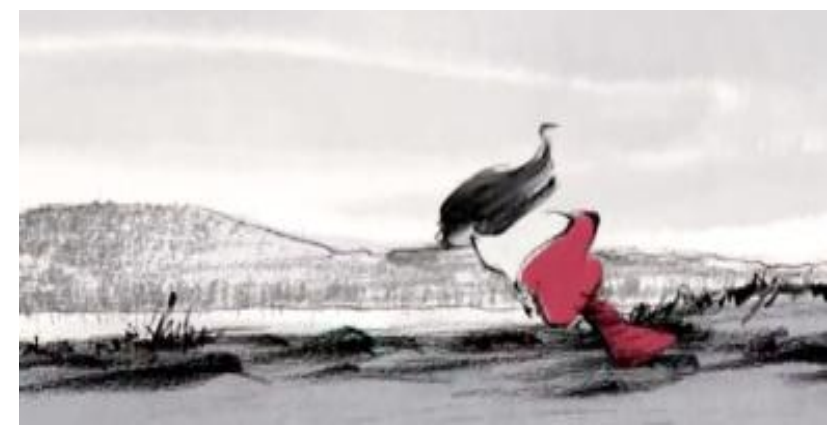

Figure 2.2.1 Princess Kaguya runs scenes (Haecke, 2014)

Based on my observation in the Figure 2.2.1 from (film duration 51:53 - 52:50) above that shows this scene when Kaguya's emotional become frustrated after she heard something bad thing that people talk about her in the ceremony to given her name. Kaguya breaks barrier after barrier and running with many camera movements in this scene. The colors used in this scene are red and white (Kaguya's outfit), the color of black, grey, and black charcoal outline present the color of background with dramatic music and hard drawn charcoal edges that push her back to her home in the woods. The color of red and white are focusing to Kaguya running with highest speed that show how Kaguya madness without thinking everyone even this scene she had fall and stand up back then running again until she arrived to her home. Kaguya become stressful with the rules in the mansion.
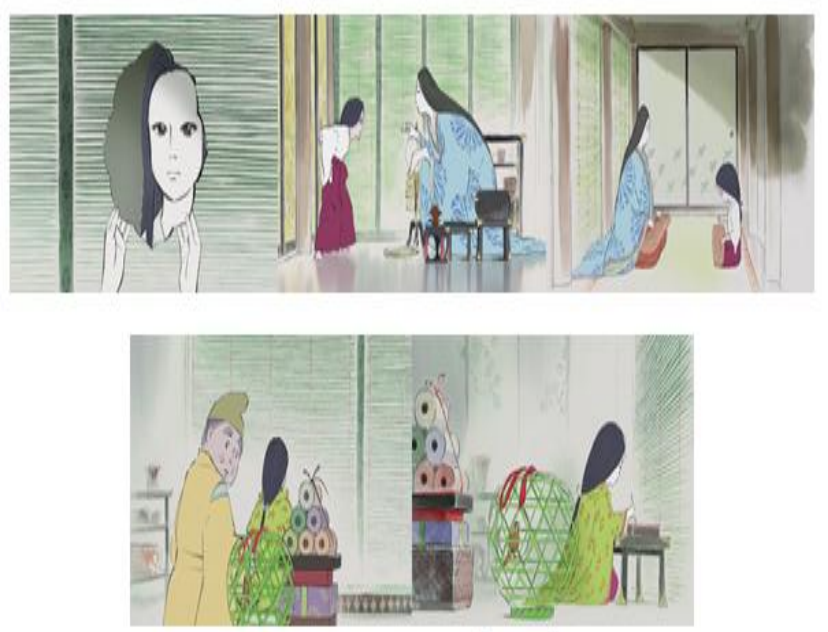

Figure 2.2.2 Green Cage (F., 2015)

Based on Yodsanklai's (2015) article, an interesting compositional element was associating the color green with the restriction of Kaguya's individuality. Green window blinds were often seen in scenes where Lady Sagami tries to corral Kaguya's free spirited personality in order to mold her into a noble princess. In these scenes she's taught proper but physically restraining posture and also told to suppress her emotions.

Even when she leaves the mansion she's metaphorically fenced in since the color of her carriage is also green. After her naming ceremony, Kaguya decided to devote herself to being a lady in order to make her father happy. She has left her playful personality behind and conformed to the restraints of nobility to acquiesce to her father's wishes. The use of green as a color of restriction was at its most poignant in this moment. Again, notice the heavy presence of green blinds but this time Kaguya is also dressed in green; the red pattern even matches the red cords of the blinds. This color trend is followed by the green bird cage with a red string, which is heavily symbolic of her situation (F., 2015). The veteran Ghibli background artist Kazuo Oga takes on an expanded role in this film as art director, producing both image boards used to define the look of the film, as well as the watercolor background art plates (Yonghow, 2014).

According to Ryan Lambie's (2015) article of interview Takahata, animation style about getting back to the purity of a simple brush-stroke to make it look as though his sketching a moment as it unfolds. He said "I chose this style because I didn't want people to forget this. The lines drawn here are not just the contours of the real things, but rather ways to instantaneously capture the expression of those things. And if there is movement, then they are the "pictures" that vividly capture the force of the movement. This technique of giving expression to the line and leaving blank spaces so that the entire surface of the painting is not filled, which engages the viewer's imagination, is one that holds an important place not only in traditional paintings of China and Japan, but also in sketches in Western drawings. What I have done is to attempt to bring this technique to animation" (Lambie, 2015).

\subsection{Character Design}

Through the myth of Japan, Princess Kaguya is the person who grew up so fast. The Japanese myths describes that Kaguya is a white skin, very beautiful with a mysterious character and has a feminism character. Kaguya has a very kind foster family to take care her until she becomes a mature woman. Due to the character of his adoptive father was a greedy and selfish wealth Kaguya had to accede to the request of the adoptive parents. Kaguya is the person who wants a simple life like her foster mother. Based on Yonghow (2015) article, the character design and visual treatment of the film is markedly different from previous Ghibli films, with a very painterly feel and subdued color tones using watercolor as the main medium. Princess Kaguya is a beautiful and poignant tale exploring sombre themes like loneliness, regret and loss (Yonghow, 2014).

Isao Takahata draws entire storyboard and sketches to capture his vision so that's the way his study process to create his film. Takahata already set up his style of animation film and he didn't use the same style to another his film. For Takahata's film "The Tale of Princess Kaguya" once he and his co-worker made it onto the storyboard but them never changes the storyboard. Takahata create a storyboard bit by bit. Hayou Miyazaki also used the same styles doing the slowly process of animation without lots of trial and error. Takahata believes as a director when this film was already completed at storyboard stage and it's become the source for the animators that's make him so interesting to making Princess Kaguya animation film. According to Ryan Lambie's (2015) article of interview Takahata, how important was it to make Princess Kaguya a modern as well 
as sympathetic character? She's headstrong and independent. Takahata said, "I have always made films sympathetic to female characters. I had no interest in presenting this tenth century literary classic as if I were unfurling an old scroll painting. I aspired to follow the original story line rather faithfully yet revive it in a lively and fresh way to give the story an entirely different impression from the original tale. That is, to narrate the "true story" of The Princess Kaguya that modern people can fully accept. The key to this approach was the concept I had of why The Princess Kaguya, who was from the Moon, came down to Earth" (Lambie, 2015).

The character attributes in The Tale of Princess Kaguya in animated film demonstrate the importance of moral value as a reflection or symbol of Japanese and Buddhist. According to Philip Kendall's (2015) article, this is a tale set in far simpler times, and although with its thick, bold brushstrokes, muted colours and incomplete lines it is quite the departure from the Ghibli releases many of us know and love, it still manages to be one of the studio's most visually striking and emotive creations to date (Kendall, 2013). The animated film of Princess Kaguya shows her appearances through how Princess Kaguya dress, she had a black hair and her hair never cut because she grows rapidly as time passes like a bamboo tree and shows her beauty. Dressed in a new robe, Bamboo runs ecstatically up a hill surmounted by a great cherry tree in full bloom. She whirls and whirls amongst showering blossoms.

According to Benbrigade's (2014) article, the beauty of the moment is intensified by its brevity and cherry blossoms are conventional symbols of transience in Japanese aesthetics, and not only for the Japanese. This is mono no aware, the pathos of things (Benbrigade, 2014).

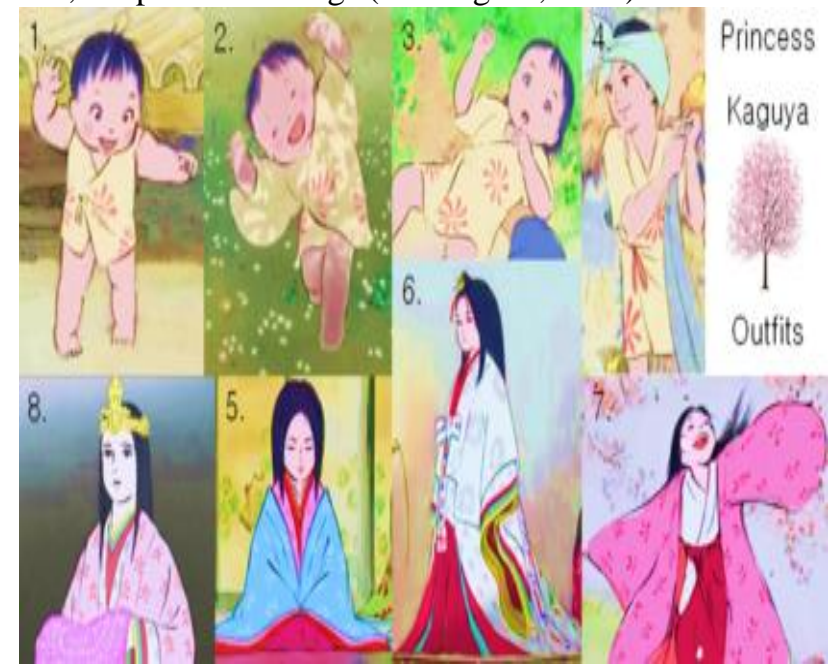

Figure 2.3.1 Princess Kaguya appearances (Lollipop, 2015)

When Princess Kaguya was a little girl, she wore a mini kimono with long-sleeves and short sleeves but the both of mini kimono have the same patterns. Princess Kaguya transformed from an ordinary human to become a real princess. She has a long straight hair wearing a beautiful kimono dress with a coat of high quality material. Coming of age, her eyebrows lifted and she was forced to wear make-up.
She was wearing her Heian Underwear (Kosode and Hakama) under a pink kimono. When Princess Kaguya was a young adult, she had to leave earth and go back to her real world at moon. On her head is a crown and she was wearing five layered kimono (Lollipop, 2015).

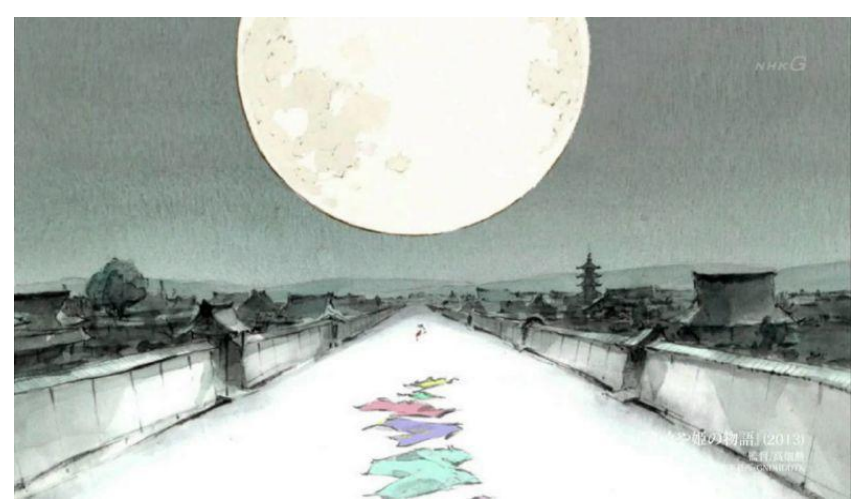

Figure 2.3.2 When Princess Kaguya run away from the mansion (Jane, 2014)

The best part of Princess Kaguya is expressive style helps to show how Kaguya adapts the surroundings people around her want or expect, especially when she's very young. Her whole-body language changes, along with her style or her way, when she's with her ambitious father compare to when she's with her friends. Kaguya run away with madness emotion throw out her heavy kimono with many layers (Figure 2.3.2). This is never remarked on or signposted, it's just shown, effortlessly, through non-verbal cues (Jane, 2014).

This story is more to the concept of heroin character where the Princess Kaguya interacts with other characters and the surroundings. It is beautiful, emotive, and undeniably haunting for this animated film. Behind everything the real pleasure that is to be had here is in experiencing the range of emotions this simple, occasionally fantastic (in the traditional sense of the word) tale evokes throughout, at once brilliant with its unique, at times almost impressionistic, art style (Kendall, 2013). This film is Takahata final feature film and he was already 79 years old in that time. If he still has the physical stamina and mental powers inside of him, Takahata wish have a miracle require he like to make another film.

\subsection{Conclusion}

So far for this chapter that I have done, I found that many articles write about their impress the art work of Isao Takahata for this animated film, The Tale of Princess Kaguya. The hand-drawn cels technique is very incredible such as ancient painting scrolls. Compare to film $M y$ Neighbors the Yamadas (1999) is not too interesting the story but their art style of the both are almost same. The My Neighbors the Yamadas was not a success the way a lot of Studio Ghibli movies were, which is a bit of a shame considering how visually expressive it was. 


\section{RESEARCH METHODOLOGY}

\subsection{Introduction}

This paper is based on a through literature review of previous research which can be used of a Studio Ghibli animated film, "The Tale of Princess Kaguya" (2013) directed by Isao Takahata, who has made other animated films, including Grave of the Fireflies (1988), Only Yesterday (1991), Pom Poko (1994), and "My Neighbors the Yamadas" (1999). This film had eight years in the making after 14 years Isao Takahata was absence. This film was adaptation of the 10th-century Japanese folk tale Taketori Monogatari that has previously inspired such cinematic adventures as Kon Ichikawa's live-action film of Princess from the Moon in 1987. Isao Takahata returned back to the big screen with The Tale of Princess Kaguya that supposed to release at the same time as The Wind Rises, a film by Studio Ghibli in 2013. But The Tale of Princess Kaguya got delayed till November 23rd 2013 and The Wind Rises released on July 20th 2013. The story is deeply significant in Japanese culture. Isao Takahata has drawn on Japanese tradition and a beautiful music in his retelling of Princess Kaguya.

This chapter presents a description of the data chosen for the analysis and addresses the methodological framework and the method of analysis. The methodology section considers the list framework of the study, focusing on language and subjectivity as its central tenets. The analytical section details the approaches taken to data analysis: thematic analysis. The final section of the methodology addresses reflexivity, providing an account of my own stance towards, and experiences in the research topic.

\subsection{Framework}

In order to come out with a proposed model for animated film, several researches that were produced by various developers have been studied. A comparative study has been done among the models and the most suitable model has been proposed. The proposed model will be discussed in next part. The Tale of Princess Kaguya animation based on the Japanese folktale to show that the importance of aesthetics and culture in film tradition of Studio Ghibli.

\subsection{Method Research}

\subsubsection{Data Collection \& Results}

Collecting data is one stage in any area of study. At this stage I plan on source thesis, reference, and the study of literature to get more information in the study.

All materials collected from research papers collected from the internet such as Websites, Digital Tutors, Google internet and videos related about The Tale of Princess
Kaguya. I've been doing research on related thesis for this film.

\subsubsection{Related Studies}

Data collect from books or other research sources. Whether library research or visual studies. It is thus to be the cornerstone of the theory of comparative data and research in the research process or study design style animation by Studio Ghibli.

\subsubsection{Observation}

The observation that I observed by watching the animated film "The Tale of Princess Kaguya" to analyze the cinematography used by Isao Takahata to show the uniqueness of the impressionistic style that used in this animated film. After that I observe to watch this animated film to evaluate every movement of characters, the concept art, style of animation and the colors used by Isao Takahata that was awarded as well as a very encouraging response. From this, I can get more information to show and prove about unique ideas and storylines produced by Studio Ghibli films.

\subsubsection{Data Analysis Methods}

After doing the data collection methods, the researchers then make data analysis methods, to produce conclusions and understanding of the study in more detail.

\subsection{The Evolution of Studio Ghibli Style Animation}

Based on figure 3.4.1 and figure 3.4.2, there are a few stages that able to consider as a production method in making research may be useful to the evolution of Studio Ghibli style animation especially in The Tale of Princess Kaguya that creation of a tradtional animated film. This research will focus the art style such the impressionistic style and character design.

It's hard to find the real method that Studio Ghibli used compare to Walt Disney method. Similarity between Studio Ghibli and Walt Disney are they used the same techniques of cel animation. Ink and paint is a very basic technique used in making animation productions. The frames are drawn by hand on tracing paper, to make the frames match up. After the frame is drawn it is transferred onto a cel, a transparent sheet of celluloid. Nowadays Disney is more focusing on 3D animation in their film industry. But Studio Ghibli still used traditional animation drawing. They just used computer to produced final production before they show on the movie. 


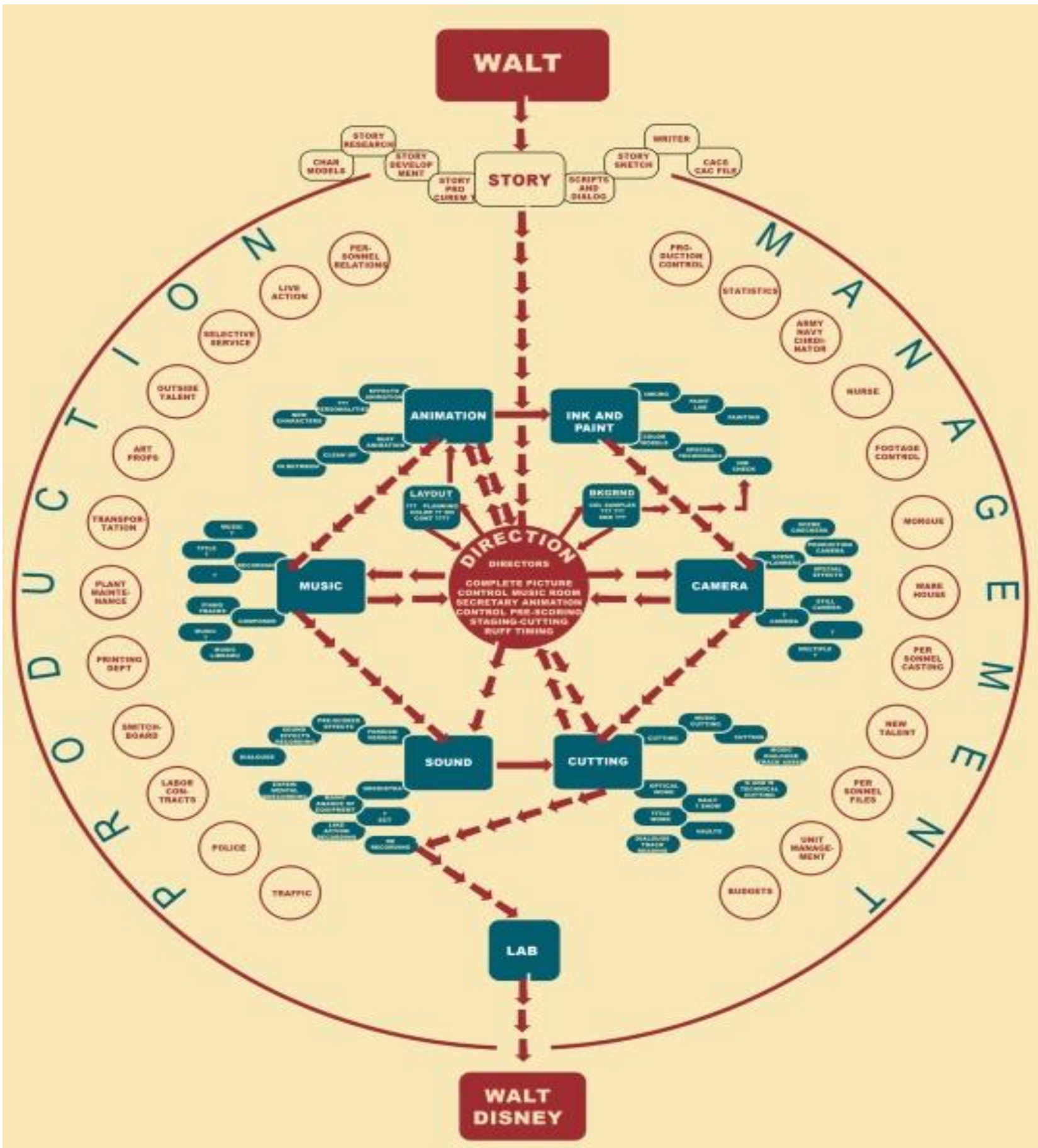

Figure 3.4.1 Walt Disney's "creative flowchart" he gave to his employees (Rebrn)

The figure 3.4.1 shows that the production pipeline chart was given by Walt Disney to his employees. The imagination of chart this being given out at an employee's orientation so they understand where they fit into the big picture (Rebrn). The flowchart of the methods above has produced the idea of Walt Disney. But I don't want to discuss about the Walt Disney. I want to focus about the production of Studio Ghibli maybe their production possibility also has the same method production just like Walt Disney method ideas.

As we know Miyazaki's preferred approach was handanimation. Miyazaki does not draw them all by himself, but he does draw much of the key animation by himself. The key animation is the backbone to the entire movie, capturing the essential movement of the animation. This differs greatly from American animation as established by Disney, which is much more of a spread-out process. Disney movies are not as much of a one-man operation as Studio Ghibli's are (Santoli, 2015). The works of Hayao Miyazaki knows that Studio Ghibli's films are marked by painstaking visual detail. Miyazaki draws entire storyboards and sketches to capture his vision. According to Studio Ghibli, they used the

Published By:

Blue Eyes Intelligence Engineering

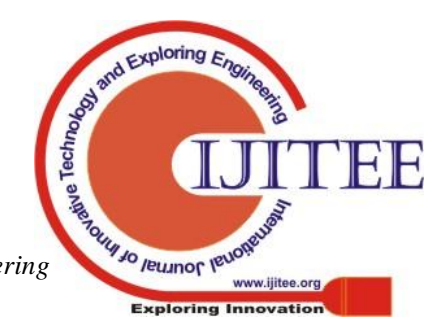


principle a feature animation for a theater, not only an original work but a studio that is a very unique worldwide presence in Japan rather than in the animation circle. This is because it is common sense that a theatrical work that cannot obtain a guarantee of box office puts in television, animation series that can earn income continuously, because the risk is too big.

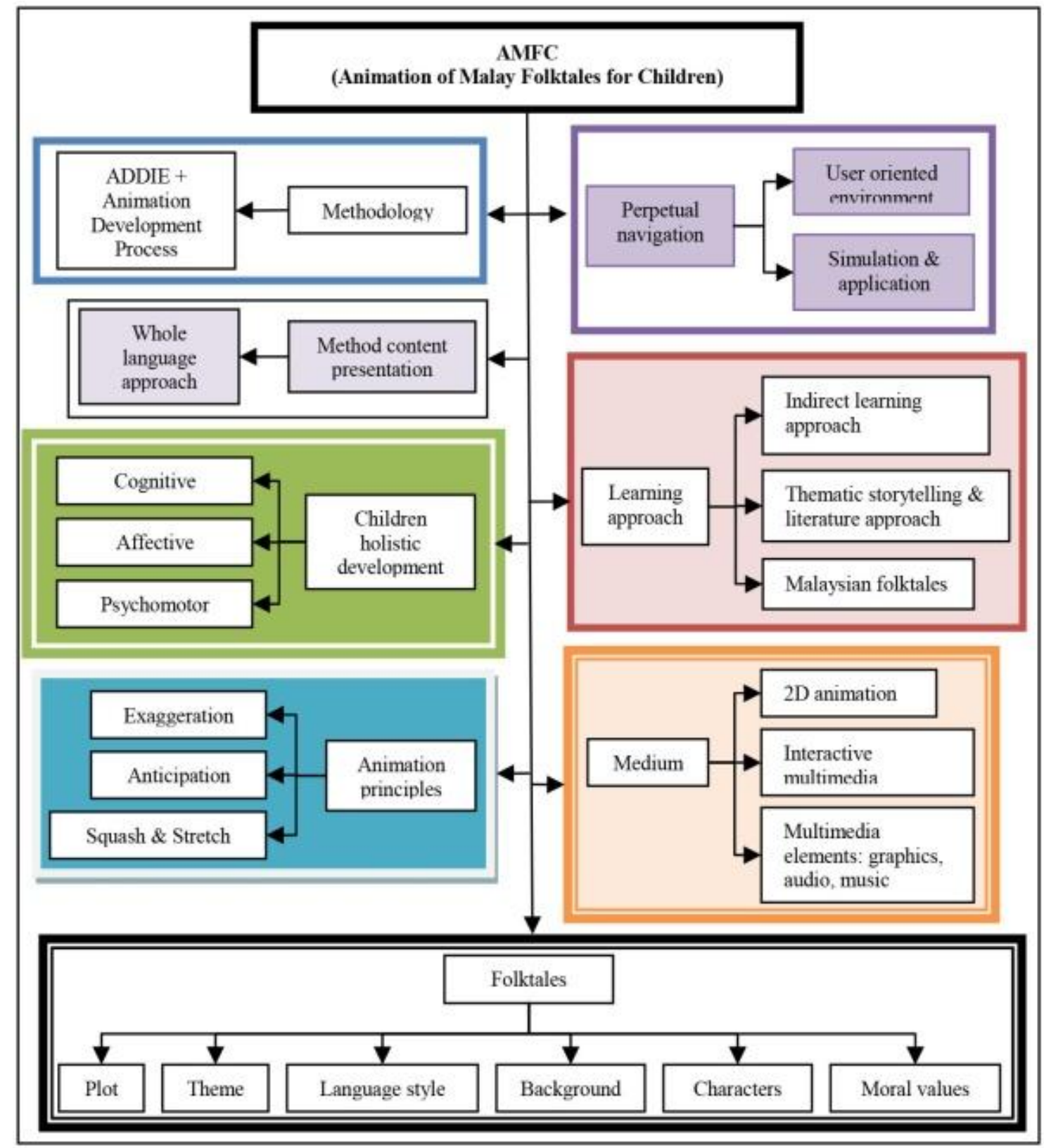

Figure 3.4.2 Animation of Malay Folktales for children (Norshahila, 2013).

Based on Norshahila Ibrahim (2013) method research, the figure 3.4.2 show the conceptual model provides a clear picture at the early stage of the project development. A complete and suitable conceptual model is important as a point of reference. Investigating the significant components for developing animation folktales is very important and several main aspects were taken into account to produce well-developed model. According to Norshahila Ibrahim (2013) article statement (figure 3.4.2); there are six elements in the form of folktales and literary highlights. The theme is an overview of hidden story. The standard story is a story that has a clear theme that can convey a particular message to the audience. Every story has a main character and usually has more than one character. Various personalities in the story depend on the story and the message to be conveyed. The plot is the storyline of a story, and the plots are divided into three parts, which are the beginning, climax and finale. The background of the story usually makes the reader think about where and when the story takes place. Generally, folktales have simple and modest spoken style (Norshahila, 2013).

This model I want to relate with Isao Takahat film's "The Tale of Princess Kaguya" that produced by Studio Ghibli. The Tale of Princess Kaguya is also based on the Japanese folktales is a film that matures suitable for the person who love classic tales and Japanese culture. The story includes the moral value as a reflection or symbol of Japanese and Buddhist. Based on learning approach method (figure 3.4.2),

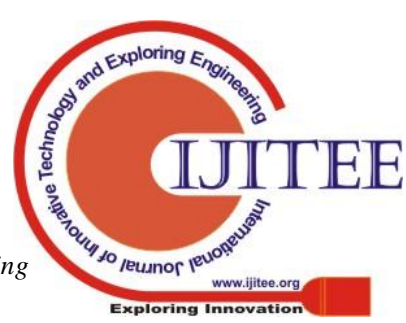


Princess Kaguya story was presented in the form of 2D animation that give the effect on users occurs through the delivery of emotional and spiritual elements in the story. The content and storylines are taken and Takahata didn't much modified from the original story.

Based on the medium (figure 3.4.2), components comprised of multimedia elements such as animation, graphics, text, audio, sound and music, and the main Ghibli introduced two computer-controlled large-scale photographing stands and launched the photography department of a wish. According to Studio Ghibli, about 100 people together with drawing department, digital painting, art, photography, video production, sound production, production and production department, work as a staff of the office work.

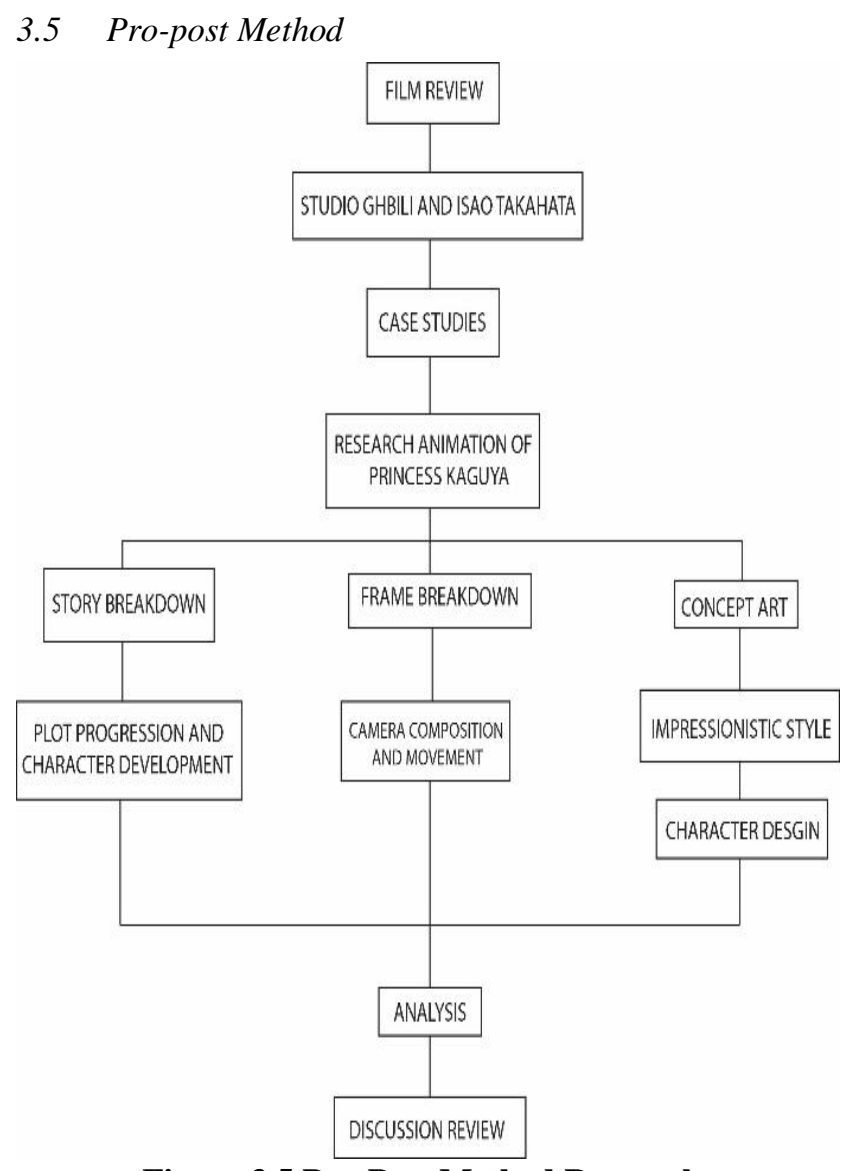

Figure 3.5 Pro-Post Method Research

Based on the Figure 3.4.1, there are a few stages to consider as a production method for the making research about the evolution of Studio Ghibli style animation and I would like to focus in The Tale of Princess Kaguya the creation based on Japanese folktale into the animation film. This research will focus the concept art arts such as impressionistic style and character design that used by Isao Takahata. This figure was based on Figure 3.4.1 and Figure 3.4.2 to analyze what kind Isao Takahata thinks about the techniques strategies from Studio Ghibli. Hayao Miyazaki and Isao Takahata style not much differ each other. This model also was developing based on this method. These models also have a relation with the method. This method show how Takahata got the ideas to produce the classic Japanese folktale into the animated film that ability to touch medium that used in many film productions. In 1993, Studio

people emotionally that make the significant to Takahata become famous. Takahata didn't use the same style to another his film. For this film Takahata chose that style because he didn't want people to forget. This research we will know Studio Ghibli is their production film just not created the animation without reason or the pursuit of popularity, Hayao Miyazaki pursued his dreams of drawing cartoons with a passion for animation, and later he would invent the iconic character that everyone identifies with as "My Neighbor Totoro." The advertisement target of Studio Ghibli to give impression towards a child's thing in Japan also follows to provide the entertainment and information. Combination between Isao Takahata and Hayao Miyazaki works are amazing towards their publication for Studio Ghibli. The reason why Takahata was so successful in all of his operations is because he carried his vision and mission over into other areas of Studio Ghibli.

The proposed model in Figure 3.5 that I make for the film review "The Tale of Princess Kaguya" that I would like to discuss. The method research that I used to collect the data is one stage in any area of study. At this stage, researchers plan on source thesis, reference, and the study of literature to get more information in the study. All materials collected from journals, textbooks and research papers collected from the internet such as Website, Digital Tutors, Google internet and videos related about Princess Kaguya animation film. I've been doing research on related thesis, including observe to watch this animated film The Tale of Princess Kaguya to learn the techniques and methods used by Isao Takahata. After collecting data, the researcher makes literature studies through library research or visual studies. From there researchers can assess any increase made by Studio Ghibli from time to time.

A pro-post research method is created in the process of making research. Researchers used the method of observation, researchers watch animated film to see every movement, concept, style, the colors used by Takahata. In the pro-post method, a case study is needed the before I research on The Tale of Princess Kaguya to understanding of this research study. From animation research, I divided into three sections. First section, I put the story breakdown to tell about the plot progression and character development of Princess Kaguya. The second section is about the frame breakdown to show how camera composition and camera movement in every scene that used in this animated film. And the last section, the concept art that include impressionistic style and character design that was created by Isao Takahata. After that, I use data analysis method to produce conclusions and understanding of the study in more detail. Data analysis method can help researchers to make inferences about the study conducted by researchers in more detail so that the thesis can be understood by the reader.

\subsection{Typology of violence from psychological research}

From the perspective of psychological research, it can be discussed that Princess Kaguya is the emotional from her soul that show how she feel herself as 'psychological 
violence' committed by her foster father ambitious in their community and the wider society under the Edo period. According to Daisuke Akimoto article based on his research of The Grave of Fireflies, these perspectives stem from the typology of violence, proposed by Johan Galtung, one of the pioneers of modern psychological research, in his paper "Violence, Peace and Peace Research" (1969), Journal of Peace Research. The typology includes a variety of violence as shown in figure 3.6.1.

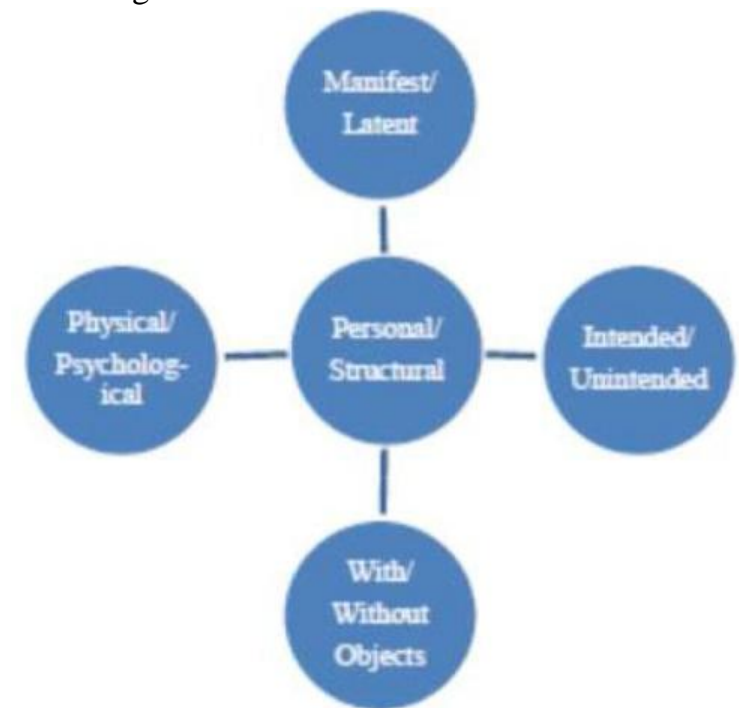

Figure 3.6.1 A simple illustration of the typology of violence by Johan Galtung (1969). The concept of 'direct/indirect violence' is implied within the depicted typology.

In the application of the typology of violence proposed by Johan Galtung (1969), Galtung is careful to include psychological violence, violence not as the direct result of one of more persons acting on one or more persons, as equal to physical violence (Akimoto). Psychological violence may take the form of simulating torture which is the treat of actual violence. Galtung also notes that inequality of a form of psychological violence, such as "when access to transportation is very unevenly distributed".

Limiting mobility, as well as limiting resources to a small class, is indirect violence. While not physical, it is something that can be prevented and therefore is a form of violence because it is something being withheld. For example, Equatorial Guinea is an oil rich nation but the wealth does not circulate beyond a select few. Most of the nation lives well below the poverty line. That essential resources are withheld when there is enough oil revenues to extend the wealth the general population, is a form of violence (Azriel, 2013). The visual style that applying to the film present abstraction in the story structure.

\subsection{Relationship of Model Method}

3.7.1 Psychological violence: Princess Kaguya was heartbroken in her royal life

The psychological violence in this film show the main character is a Princess Kaguya the girl who was looked after by a couple married who had no children after the bamboo cutter found her at the shinning bamboo stalk in the forest. Right from the beginning, the movie lets the audience know that the main character, Princess Kaguya is a girl who grows up so fast and she starts narrating what happened to her and her family until they had to move at the capital because her foster father requests to start a new life "royal life". Desire or expectation Kaguya to getting a normal life is so thin. Property acquired by her family because of the gift from the heaven. Her father believes the gift from heaven can give Kaguya happiness but not at all. Her father already set up her life to become a real princess to enjoy the royal life and the immediacy of nature and her father's belief in her noble destiny pushes that life away. He forcing Kaguya to leaves her friend behind because he thinks that Kaguya's friends are not suitable make friends with her.

The film depicts not only the beauty of Princess Kaguya but also how they desperate live in a royal life that able to relate as 'psychological violence'. Kaguya feels like slave's girl who have to follow all regulations arranged in a mansion. She just likes a bird in a cage. There is one scene shows Kaguya was writing calligraphy at the same time his father had brought the gifts given by the princes. Kaguya was given the task by the Lady Sagami to taming her become a noblewoman. In these scenes she's taught proper but physically restraining posture and also told to suppress her emotions.

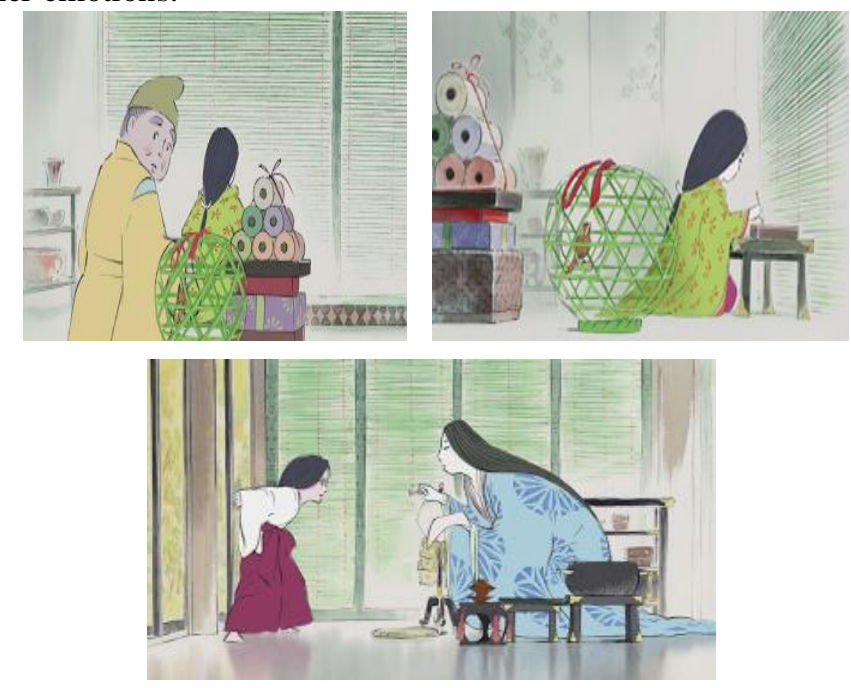

Figure 3.7.1 Green Cage (F., 2015)

Finally, Kaguya makes up her mind to become a real princess and to live in their mansion. This part of the movie narrates the negative aspect of human nature by forcing someone else to become what they want even their own child.

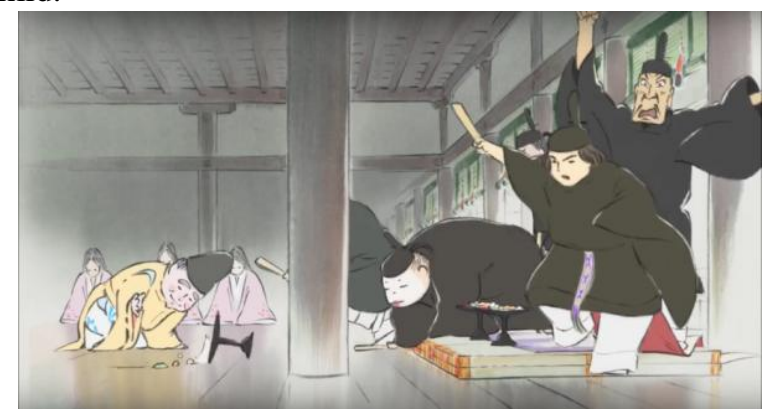

Figure 3.7.2 The five suitors trying to marry or somehow possess the princess (Kneipp, 2017)

Blue Eyes Intelligence Engineering

\& Sciences Publication 
The five princes want to marry with Kaguya after they heard about her beauty is more beautiful than a human being. Kaguya has given order to them proved their love by completing the impossible tasks. Kaguya was forced to make an order for avoiding her from marrying one of the princes. Kaguya fell into depression when one of the men is killed in his quest. This scene shows Princess Kaguya increasingly feeling of guilty and frustrated just like her killed someone but it doesn't stop the Emperor for attempting to force his attentions on her. After that the Emperor come to her mansion can see her face was so beautiful, the Emperor took the opportunity to get her with evil desires. But Kaguya aware of the act of the Emperor was degrading to herself. I think that scene was shocked show that Princess Kaguya had suffered in her royal life. These parts without her father protection and support just like Kaguya's father seems as a servant must obey the order from noblemen without thinking about his own daughter feelings. Kaguya's father made a reckless decision making forced toward her to follow his order but Kaguya has refused her father request for married with the Emperor. Kaguya had threatened his father if his father doesn't want to disobey an order from the Emperor she wants to kill herself. In the Figure 3.7.3, below that I had print screen from the movie to show the scene Kaguya refuse her father request. Some of the text of translation from the movie that I took in the scene (duration film 1:40:15 - 1:40:45);

"If you wish to accuse me of disobedience to His Majesty, then feel free to kill me...If your happiness depends on a courtier's cap, then I will go to him... When I see you wearing that cap, then I will kill myself'".

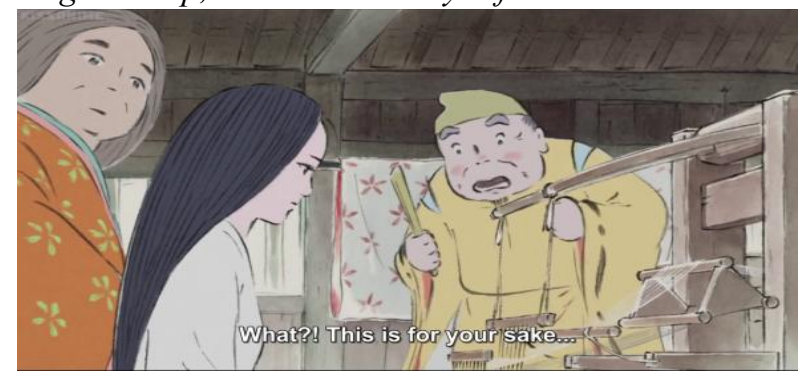

Figure 3.7.3 Kaguya refuse her father request (duration film 1:40:15 - 1:40:45)

This scene clearly depicts how Kaguya overcome 'psychological violence' in order to survive and to protect her dignity family and Kaguya had to turn backs on her misery.

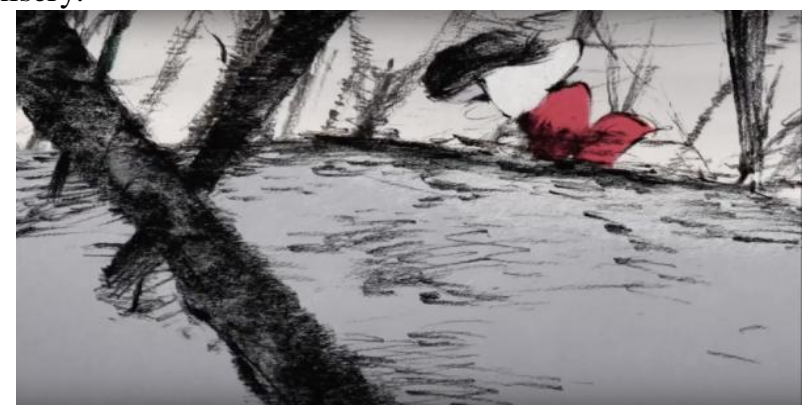

Figure 3.7.4 The princess escaping back to her village in a charcoal drawn dream sequence (Kneipp, 2017)

According to Jessica Kneipp (2017) article statement, in one of the most explosive sequences of the film, the princess bursts through the walls of the prison that her father and society built around her. Barrier after barrier, she breaks through, escaping at high speed with dramatic music and hard drawn charcoal edges that push her back to her home in the woods, the place where she was raised. When she arrives, she sees that everyone from the village has gone and the place has changed. She eventually falls asleep in the snow, only to wake up back at the palace (Kneipp, 2017).

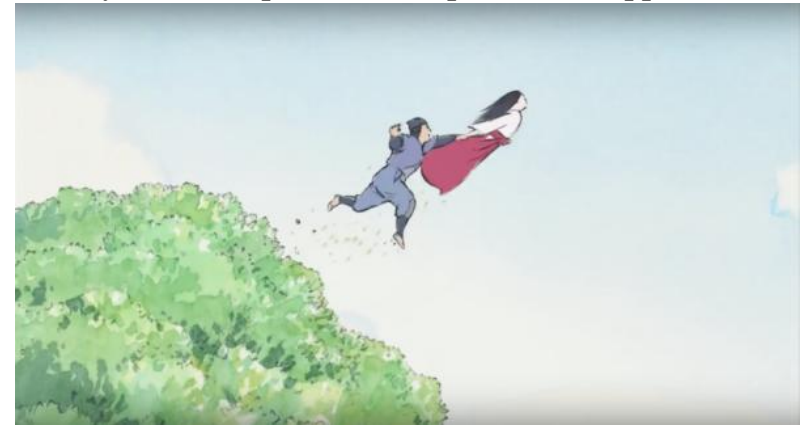

Figure 3.7.5 The sequence where the princess is living her ideal life with her true love (Kneipp, 2017)

Behind the suffering endured by Kaguya, Kaguya has feeling of love towards Sutemaru where there is a scene Kaguya and Sutemaru are flying together in Figure 3.7.5. They are falling in love each other that make them feel happiness although it's temporary. At that moment Kaguya was feeling peaceful but she realized that his love was delayed because of Kaguya is a person who are not origin from the earth. Kaguya and Sutemaru life are very much different to live together. She is not ordinary human being but she is person who came from the moon. Their love seemed a dream for Sutemaru. This scene shows the happiness that Kaguya dreamed was impossible for her to earn in her life. This is not fair for Kaguya why she had sent to the earth. She was suffering with her love, her life and her family. The final scene show that her parent watch Kaguya wearing the robe and she need to leave about her life on earth. She ascends to the moon, leaving her parent in distress as Kaguya looks back for one last time with tears in her eyes. Kaguya rebuke herself telling that life on earth are full of wonder.

Although the film is fictionalized based on the Japanese folktale, Kaguya's psychological violence against her life in the earth brings her the bittersweet memory. She is a girl who struggles with her own environment. There are a lot of questions about why Kaguya sent to earth? I have no idea maybe she got a punishment because many years researcher had covered over the concept of this 'old promise'.

\subsection{Summary}

I discussed the film "The Tale of Princess Kaguya" directed by Isao Takahata on several researches the suitable model has been proposed to evaluate Studio Ghibli style animation. The terms of psychological research in the film that method was based on Daisuke Akimoto article based on his research of The Grave of Fireflies. He applied typology of violence proposed by Johan Galtung in 1969. 


\section{REFERENCES}

1 Akimoto, D. (n.d.). Peace education through the animated film "Grave of the Fireflies". Retrieved from www.apu.ac.jp/rcaps/uploads/fckeditor/publications/.../R JAPS33_4_Akimoto.pdf

2 Anders, C. J. (2014, 10 20). Don't Deprive Yourself Of Seeing The Beauty Of Princess Kaguya. Retrieved 1020 , 2014, from Gizmado : http://io9.gizmodo.com/dontdeprive-yourself-of-seeing-the-beauty-of-princess1648552243

3 Azriel. (2013, December 9). Johan Galtung's six dimensions of violence. Retrieved December 9, 2013, from All My Neighbors: http://allmyneighbors.org/2013/12/09/johan-galtungs-sixdimensions-of-violence/

4 Beal, V. (n.d.). Cel Animation. Retrieved from Webopedia:http://www.webopedia.com/TERM/C/cel_ani mation.html

5 Belton, N. (2016, April 22). The Tale of Princess Kaguya. Retrieved April 22, 2016, from characterdesignreferences:

https://characterdesignreferences.com/movie-reviews-

1/the-tale-of-princess-kaguya

6 Benbrigade. (2014, October 27). The Tale of the Princess Kaguya (2014). Retrieved October 27, 2014, from Benbrigade's Blog: https://benbrigade.wordpress.com/2014/10/27/the-taleof-the-princess-kaguya-2014/

7 chuck-526. (2015, January 24). Reviews \& Ratings for The Tale of Princess Kaguya. Retrieved January 24 2015, from IMDb Website: http://www.imdb.com/title/tt2576852/reviews

8 Eric, L. (2015, October 4). The Tale of Princess Kaguya. Retrieved October 4, 2015, from Studio Ghibli Wiki: http://studio-

ghibli.wikia.com/wiki/The Tale of Princess_Kaguya

9 F., Y. (2015, February 22). The Tale of the Princess Kaguya. Retrieved February 22, 2015, from animecinematography:

http://animecinematography.blogspot.my/2015/02/thetale-of-princess-kaguya.html

10 Friesen, J. (2014, September 29). Reviews \& Ratings for The Tale of Princess Kaguya. Retrieved September 29, 2014, from IMDb Website: http://www.imdb.com/title/tt2576852/reviews

11 Ghibli, S. (2005-2017). History of Studio Ghibli. Retrieved 2005-2017, from STUDIO GHIBLI Inc.: http://www.ghibli.jp/history/

12 Haecke, P.-J. V. (2014, August). The Tale of Princess Kaguya (review). Retrieved from psychocinematography: https://psychocinematography.wordpress.com/movies/the -tale-of-princess-kaguya/the-tale-of-princess-kaguyareview/

13 Jane, C. (2014, 10 20). Don't Deprive Yourself Of Seeing The Beauty Of Princess Kaguya. Retrieved 10 20, 2014, from Gizmodo: http://io9.gizmodo.com/dont-depriveyourself-of-seeing-the-beauty-of-princess-1648552243

14 Kendall, P. (2013, November 26). Kaguya Hime no Monogatari: The other side of Studio Ghibli [Review】. Retrieved November 26, 2013, from RocketNews24: http://en.rocketnews24.com/2013/11/26/kaguya-hime-nomonogatari-the-other-side-of-studio-ghibli-

\%E3\%80\%90review\%E3\%80\%91/

15 Kermode, M. (2015, March 22). The Tale of the Princess Kaguya - 'a beautiful historical fantasia'. Retrieved March 22, 2015, from theguardian: https://www.theguardian.com/film/2015/mar/22/tale-ofprincess-kaguya-review-kermode

16 Kneipp, J. (2017, March 24). The Endless Visual Beauty of 'The Tale of the Princess Kaguya'. Retrieved March
24, 2017, from Vision Times: http://www.visiontimes.com/2017/03/24/the-endlessvisual-beauty-of-the-tale-of-the-princess-kaguya.html

17 labelleequipe25. (2013, December 5). Reviews \& Ratings for The Tale of Princess . Retrieved December 5, 2013, from IMDb Website http://www.imdb.com/title/tt2576852/reviews

18 Lambie, R. (2015, March 17). Isao Takahata interview: The Tale Of The Princess Kaguya. Retrieved March 17, 2015, from http://www.denofgeek.com/us/movies/studioghibli/244690/isao-takahata-interview-the-tale-of-theprincess-kaguya

19 Lollipop, K. (2015, April 1). Kaguya outfits. Retrieved April 1, 2015, from Studio Ghibli Wiki: http://studioghibli.wikia.com/wiki/Kaguya?action=edit\&section=1

20 Norshahila. (2013, December 4). A Proposed Model for Animation of Malay Folktales for Children. Retrieved December 4, 2013, from http://is.its.ac.id/pubs/oajis/index.php/home/detail/1222/ A-Proposed-Model-for-Animation-of-Malay-Folktalesfor-Children

21 Rebrn. (n.d.). Walt Disney's "creative flowchart" he gave to his employees. Retrieved from Rebrn: http://rebrn.com/re/walt-disneys-creative-flowchart-hegave-to-his-employees-1000419/

22 Sanders, A.-L. (2016, September 30). 2D Animation Retrieved September 30, 2016, from http://animation.about.com/od/glossaryofterms/g/2danim _def.htm

23 Santoli, E. A. (2015, January 15). Hayao Miyazaki's Drawing and Watercolor Technique. Retrieved January 15, 2015, from Fanboys Anonymous: http://www.fanboysanonymous.com/2015/01/hayaomiyazakis-drawing-and-watercolor.html

24 Yonghow. (2014, February 2). The Art Of Kaguyahime Book Review. Retrieved February 2, 2014, from halcyonrealms:

http://cdn.halcyonrealms.com/animation/the-art-ofkaguyahime-book-review/

25 Zobras. (2014, December 10). Reviews \& Ratings for The Tale of Princess Kaguya. Retrieved December 10, 2014, from IMDb Website: http://www.imdb.com/title/tt2576852/reviews 